\title{
Isolation, Characterization, and Distribution of an Unusual Pancreatic Human Secretory Protein
}

\author{
Jerome Gross, Rolf I. Carlson, Andrew W. Brauer, Michael N. Margolies, Andrew L. Warshaw, and́ Jack R. Wands \\ Developmental Biology Laboratory and Gastrointestinal Laboratory, Medical Services; and Cellular and Molecular Research Laboratory \\ of the Surgical and Medical Services, and Gastrointestinal Surgery Research Laboratory of the Surgical Services, \\ Massachusetts General Hospital, and Harvard Medical School, Boston, Massachusetts 02114
}

\begin{abstract}
An unusual protein was isolated from acid extracts of normal human pancreas and pancreatic secretion in the form of uniform 7-10-nm long single threads without visible axial periodicity or other structure, as seen in the electron microscope. It accounts for as much as $300 \mu \mathrm{g} / \mathrm{ml}$ in some pancreatic secretions as measured by specific radioimmunoassay. The protein undergoes a freely reversible, pH dependent, globule-fibril transformation, being stable in the fibril form between $\mathrm{pH} 5.4$ and 9.2. The monomer at acid $\mathrm{pH}$ has an apparent molecular weight of $\sim 14,000$ and consists of a single polypeptide chain, the amino acid composition of which is rich in aromatic amino acids and lacks carbohydrate, fatty acid, and phosphate. The amino acid sequence of $\mathbf{4 5}$ residues from the amino terminus shows no homology with any other reported protein sequences other than that of the A chain of the bovine pancreas thread protein (reported elsewhere). A sensitive radioimmunoassay employing monoclonal antibodies against human pancreatic thread protein failed to detect the antigen in a wide range of human tissues other than pancreas, nor was the antigen measurable in normal human sera. Immunohistochemistry utilizing these antibodies revealed the antigen as a component of the cytoplasm of some but not all the pancreatic acinar cells. A physiologic function has not yet been determined for this protein.
\end{abstract}

\section{Introduction}

An early effort to study the molecular structure of elastin by electron microscopy after enzymatic digestion with trypsin led to a misinterpretation of the supramolecular organization of elastin (1) and to the discovery of an unusual filamentous contaminant present in "purified", crystallized, bovine trypsinogen (2). Subsequently, this protein was shown to exhibit readily reversible, $\mathrm{pH}$ dependent thread-like polymerization (3). The phenomenon of globule-fibril transformation was of considerable interest to cell and molecular biologists of the time since it seemed to provide a clue to understanding the changing physical properties of cytoplasm. Related molecular properties had, during this early period of electron microscopic studies of biopolymers, also been described for insulin (4), actin (5), and tropomyosin

This is publication No. 984 from the Robert W. Lovett Group for the Study of Diseases Causing Deformities.

Address reprint requests to Dr. Gross, Developmental Biology Laboratory, Massachusetts General Hospital, Boston, MA 02114.

Received for publication 1 May 1985.

J. Clin. Invest.

(C) The American Society for Clinical Investigation, Inc.

$0021-9738 / 85 / 12 / 2115 / 12 \quad \$ 1.00$

Volume 76, December 1985, 2115-2126
(6). However, the conditions for fibril formation of these proteins are widely different from those of the protein described here.

The bovine pancreatic thread protein (PTP) ${ }^{1}$ proved to be a by-product (3) of the commercial preparation of purified pancreatic enzymes (7). It appeared as a gelled precipitate forming during an intermediate stage in the isolation procedure. This insoluble contaminant of commercial crystallized trypsin consisted of tight, uniformly wound, double helical strands $\sim 12$ $\mathrm{nm}$ in diameter, each strand being smooth, $\sim 7 \mathrm{~nm}$ in width, and was occasionally seen singly or in parallel pairs $(1,2)$. The same structure was found in threads isolated from fresh bovine pancreas (8). This protein, rich in aromatic amino acids, has a molecular weight in acid solution of $\sim 17,800$ and consists of two polypeptide chains differing in léngth and amino acid sequence. The $\mathrm{NH}_{2}$-terminal 48 residues of one chain (A) and 35 residues of the other (B) appeared to be unique among all reported amino acid sequences for other proteins (8).

In 1970 (Gross, unpublished observations) a similar protein was isolated from postmortem human pancreas by the same extraction procedure used for bovine pancreas. We report here the isolation and partial characterization of this protein, now designated human pancreatic thread protein (PTP) from normal human pancreas and from pancreatic secretion. Monoclonal antibodies have been prepared against the purified protein and were used in the development of a sensitive radioimmunoassay to measure human PTP in tissue extracts and other body fluids. The antibodies have also been employed in cellular localization by immunohistochemical techniques.

\section{Methods}

Preparation of PTP. Human pancreas tissue $(\sim 500 \mathrm{~g})$ obtained at various times postmortem was immediately immersed in cold $0.25-\mathrm{M}$ sulfuric acid, homogenized in a blender in an ice bath, then stirred mechanically for $24 \mathrm{~h}$. The cloudy suspension was first filtered through cheese cloth and then centrifuged at high speed. The opalestent supernatant fluid was separated from the floating and sedimented fat and tissue debris followed by filtration through \#1 filter paper (Whatman Inc., Clifton, NJ) covered with a 1-in layer of Celite.

The slightly cloudy nonviscous solution was then fractionated by successive ammonium sulfate precipitation and re-solution according to the procedure of Kunitz and Northrup (7) for the preparation of pancreatic proteases. The preparation protocol was identical to that used in an accompanying study of bovine PTP (8). The precipitate obtained from the third $70 \%$ saturated ammonium sulfate fraction dissolved in water was adjusted to $\mathrm{pH} 8.0$ with sodium bicarbonate and allowed to stand overnight at $4^{\circ} \mathrm{C}$ until an opalescent suspension of globular aggregates formed. The precipitate that was removed by sedimentation at $20,000 \mathrm{~g}$ (after examination by light microscopy) contained the threads as shown by electron microscopy. The pellet dissolved rapidly in $0.1 \mathrm{M}$

1. Abbreviations used in this paper: ELISA, enzyme-linked immunosorbent assay; PAS, Periodic Acid Schiff; Pth, phenylthiohydantoin; PTP, pancreatic thread protein. 
$\mathrm{HCl}$ and centrifugation removed a small amount of insoluble material. The water-clear, nonviscous solution was neutralized with $\mathrm{NaOH}$ to $\mathrm{pH}$ 7.0; this produced a large, loosely gelled, opalescent precipitate that appeared rapidly and gradually settled. This cycle of acid solution and neutral precipitation was repeated four or five times before lyophilizing the purified material from distilled water to a white cotton-like fluff. Acid extracts of $1-5 \mathrm{~g}$ of fresh pancreatic tissue obtained at surgery from patients with pancreatic carcinoma, pseudocysts, and chronic pancreatitis were prepared for assay for, and preparation of, PTP.

Preparation of thread protein from pancreatic secretion. 2 liters of pancreatic fluid was obtained from an indwelling pancreatic duct catheter in a patient who had undergone surgery for correction of recurrent pancreatitis due to pancreas divisum. The fluid, which had been immediately frozen on collection, was very cloudy on thawing. The white, well packed sediment obtained by sedimentation at $20,000 \mathrm{~g}$ for $30 \mathrm{~min}$, dissolved rapidly in cold $0.1 \mathrm{M} \mathrm{HCl}$. It was centrifuged again to remove a small amount of insoluble material before precipitation by neutralization with $\mathrm{NaOH}$. Precipitation and re-solution was repeated three or four times before lyophilization of the final precipitate dispersed in water. Other smaller samples of fresh pancreatic fluid were obtained by catheters postoperatively from patients having undergone the Whipple operation for intractable chronic pancreatitis or pancreatic carcinoma.

Phase, polarized light, and electron microscopy. Drops of unstirred thread suspension spontaneously aggregated as microglobules in the solution of the third $70 \%$ saturated ammonium sulfate precipitate from pancreatic extract, before $\mathrm{pH}$ cycling purification, were examined directly in phase and polarizing microscopes. The quarter wave (Red I) plate was used in the latter for determination of birefringence polarity (positive or negative with respect to the long axis) of the molecular components of the spherites.

Drops of purified threads derived from both the tissue extracts and the secreted fluid in the neutral $\mathrm{pH}$ range were allowed to sit briefly on carbon-formvar coated grids, then were negatively stained with sodium siliocotungstate at $\mathrm{pH}$ 7.4. Some grids were shadowed with chromium at a $10^{\circ} \mathrm{C}$ angle. A JEOLCO Model $100 \mathrm{~B}$ electron microscope was used at $80 \mathrm{kV}$ to examine these preparations.

pH dependence of solubility. $2 \mathrm{mg}$ of purified PTP from pancreatic secretion was dissolved in $1 \mathrm{ml}$ of citrate-phosphate buffer at $14 \mathrm{pH}$ values between 2.6 and 10.5 . After standing at $4^{\circ} \mathrm{C}$ overnight the suspensions were clarified in a microfuge (Beckman Instruments, Inc., Fullerton, CA) and the clear supernatant fluids were diluted to concentrations suitable for spectrophotometry at $280 \mathrm{~nm}$.

Amino acid, sugar, and phosphate analyses. Hydrolysis of thread protein obtained from extracts of pancreas was accomplished in $3 \mathrm{~N} \mathrm{p}$ toluenesulphonic acid containing 0.2\% 3-(aminoethyl)indole as described by Liu and Chang (9) in order to preserve tryptophan. Recovery of all other amino acids after hydrolysis was established for each one separately. Analyses were performed in an amino acid analyzer (model 121 B; Beckman Instruments, Inc.) using a single column system according to the protocol of Trelstad and Lawley (10).

Gas liquid chromatographic analysis for sugars was accomplished by the method of Rheinhold (11) and analysis for fatty acids was accomplished by the procedure of Heckers et al. (12), courtesy of Keyes Linsley in the laboratory of Dr. Roger Jeanloz (Massachusetts General Hospital). This procedure for sugars will detect and measure both neutral and acidic types.

The phosphate content was analyzed chromatographically on a Beckman 121M amino acid analyzer as phosphoserine and phosphothreonine after $\mathrm{HCl}$ hydrolysis as described by Cohen-Solal, et al (13), courtesy of Dr. Melvin Glimcher (Childrens Medical Center, Boston, MA).

Reduction and alkylation. $5 \mathrm{mg}$ of lyophilized human PTP was dissolved in $6 \mathrm{M}$ guanidine hydrochloride in Tris- $\mathrm{HCl} 0.5 \mathrm{M}$, pH 8.2 plus $5 \mathrm{mM}$ EDTA. Dithiothreitol, $20 \mathrm{mM}$, was added and after flushing with $\mathrm{N}_{2}$ and incubation at $37^{\circ} \mathrm{C}$ for $90 \mathrm{~min}$ the protein was alkylated at $4^{\circ} \mathrm{C}$ in the dark with $100 \mu \mathrm{l}$ of buffer containing $9.4 \mathrm{mg}$ unlabeled iodoacetamide and $100 \mu \mathrm{Ci}$ iodo $\left[{ }^{14} \mathrm{C}\right]$ acetamide $(23.6 \mathrm{mCi} / \mathrm{mmol})$. The reaction was stopped with $0.1 \mathrm{M}$ acetic acid and the preparation was dialyzed against $0.01 \mathrm{~N} \mathrm{HCl}$.
Polyacrylamide gel electrophoresis. Protein heterogeneity and apparent molecular weight were evaluated by $\mathrm{NaDodSO}_{4}$ polyacrylamide gel $(11 \%, 14 \%, 15 \%)$ electrophoresis using molecular weight markers. Reduced and radioalkylated preparations were also analyzed by the radioautographic procedure of Laemmli (14).

The relationship between the thread protein and neutral protease activity, shown to be present by radioactive gelatin assay (15), was assessed by electrophoresis in an $11 \% \mathrm{NaDodSO}_{4}$ acrylamide gel that included $1.5 \%$ of gelatin (16). Purified crystalline bovine trypsin (Sigma Chemical Co., St. Louis, MO), $50 \mathrm{ng}$, was included as a control of the method, and as a standard in a separate lane. At the end of the run, $\mathrm{NaDodSO}_{4}$ was eluted with $2.5 \%$ Triton $\mathrm{X}$ for $1 \mathrm{~h}$ at room temperature after which the gel was incubated at $37^{\circ} \mathrm{C}$ for $4 \mathrm{~h}$ in a neutral buffer, then stained with Coomassie Blue. Both the assay and electrophoretic separation were kindly performed by Yi-Shan Cheng of the Developmental Biology laboratory, Massachusetts General Hospital, Boston, MA.

Purified human PTP was electrophoresed under nonreducing conditions on a $12.5 \%$ polyacrylamide slab gel containing $0.1 \% \mathrm{NaDodSO}_{4}$. Without fixation, lanes containing the protein were excised from the gel and individually sliced into $2-\mathrm{mm}$ sections. The sections were then placed into $100-\mu \mathrm{l}$ aliquots of PBS for $16 \mathrm{~h}$ at $20^{\circ} \mathrm{C}$ to elute electrophoresed protein from the gel. Immunoactivity of the eluate was determined by using the radioimmunoassay described herein. Parallel lanes containing electrophoresed protein and molecular weight markers were visualized after fixation and Coomassie Blue staining.

Amino acid sequence analysis. Gas phase sequencing was accomplished with an Applied Biosystems model 470A instrument (Applied Biosystems, Inc., Foster City, CA) on 3-6-nmol samples of intact thread protein with and without reduction-alkylation using the MHTFAI program (Applied Biosystems, Inc.) as described (8). Phenylthiohydantoin (Pth) amino acids were identified and quantified by high pressure liquid chromatography as previously reported (17). The location of cysteine residues was determined by measuring radioactivity of Pth amino acids at each cycle in the analysis of the reduced and radioalkylated sample. Reduction with dithiothreitol and alkylation with iodo $\left[{ }^{24} \mathrm{C}\right]$ acetamide was accomplished as described above.

Production and characterization of monoclonal antibodies. Primary immunization of female BALB/c mice was performed intraperitoneally using $25 \mu \mathrm{g}$ of purified human PTP in 50\% complete Freund's adjuvant. A 6-10-wk interval was allowed followed by a 10- $\mu \mathrm{g}$ boost in $100 \mu \mathrm{l}$ normal saline delivered intravenously. $3 \mathrm{~d}$ thereafter, the spleen was removed and isolated splenocytes fused with the NS1 myeloma cell line according to previously reported protocols for soluble proteins $(18,19)$. Maintenance and cloning of hybrids as well as production of ascites were as previously described (19).

We developed an enzyme-linked immunosorbent assay (ELISA) for the detection of anti-human PTP producing hybrids. In brief, 96-well polystyrene plates were coated with acid-dissolved, purified PTP $(40 \mu \mathrm{g} /$ well) followed by incubation with hybrid cell culture supernatant fluids. The plates were washed with buffer, incubated with goat anti-mouse antibodies conjugated to horseradish peroxidase, then developed and read with an ELISA reader as previously described (18). Similarly, the isotypes of the anti-PTP antibodies were determined with specific goat anti-mouse $\operatorname{IgG}_{1}, \operatorname{IgG}_{2 \mathrm{a}}, \operatorname{IgG}_{2 \mathrm{~b}}, \operatorname{IgG}_{3}$, and IgM reagents (18).

We determined if the various anti-PTP antibodies recognized the same, closely related or distinctly different epitopes on human PTP by competitive binding experiments. For this procedure the protein was deposited from acid solution on the solid phase support as described above. ${ }^{125}$ I-labeled monoclonal anti-PTP antibodies $(100,000 \mathrm{cpm})$ were incubated with increasing amounts of unlabeled homologous antibody to generate an inhibition curve. Next, the unlabeled homologous antibody was substituted by a different unlabeled anti-PTP antibody (from another clone) and the radioactivity bound to the wells determined at increasing antibody concentrations. If, for example, no inhibition of binding was observed under these conditions, we may conclude that the second unlabeled antibody recognized a separate and distinct determinant on the antigen (20).

Radioimmunoassay for human PTP. Monoclonal antibodies from double clonal cell lines of the IgG subclasses were purified for further 
study using Sepharose 4B staphylococcal protein A affinity columns (Pharmacia Fine Chemicals, Piscataway, NJ). $1 \mathrm{ml}$ of centrifuged, filtered ascites fluid was placed on the column at $\mathrm{pH}$ 8.0. The ascites fluid was allowed to remain on the column without washing for $30 \mathrm{~min}$ at $4^{\circ} \mathrm{C}$ after which the column was washed with phosphate-buffered saline (PBS) at $\mathrm{pH} 8.0$ and mouse IgG isotypes were eluted sequentially with various buffers according to a previously established protocol (19). Purified antibodies thus obtained were dialyzed overnight against $0.15 \mathrm{~N} \mathrm{NaCl}$ twice and the protein concentration was determined by the Lowry method (21) using bovine serum albumin as the protein standard. Iodination of the antibodies to specific activity varying between 10 and $15 \mu \mathrm{Ci} / \mu \mathrm{g}$ with

${ }^{125}$ I was accomplished by the Iodogen method (22).

Radioimmunoassay (RIA) was used for detecting and measuring human PTP in extracts of various tissues including pancreas, and pancreatic secretions. 1-10 $\mathrm{g}$ of fresh human tissue obtained at surgery or postmortem were collected in cold $0.25 \mathrm{M} \mathrm{H}_{2} \mathrm{SO}_{4}$, homogenized, centrifuged, and filtered to obtain clear or faintly opalescent extracts. These were neutralized to $\mathrm{pH} 7-7.6$ with $\mathrm{NaOH}$ at $4^{\circ} \mathrm{C}$ and assayed directly. RIA was performed as follows: $1 / 4$-in polystyrene beads (Precision Plastic Ball Co., Chicago, IL) were coated with dilutions of ascites fluid (range, $1: 100$ to $1: 1,000$ ) in PBS, pH 7.2, containing the antibody of interest. After a 16-h incubation of the solid phase support with dilutions of ascites fluid at $20^{\circ} \mathrm{C}$, the beads were washed three times with distilled water and then incubated with $200 \mu$ of various biologic fluids, protein solutions, and tissue extracts. In addition, we explored various monoclonal antibodies bound to the solid phase support, either alone or in combination, in an attempt to optimize the sensitivity of the RIAs; the radiolabeled indicator antibody consisted of a ${ }^{125} \mathrm{I}$-anti-PTP monoclonal antibody identical to one linked to the solid phase support. The radiolabeled indicator antibody $(100,000 \mathrm{cpm}, \mathrm{sp}$ act, $10-15 \mu \mathrm{Ci} / \mu \mathrm{g})$ diluted in PBS$50 \%$ fetal calf serum $(100 \mu \mathrm{l})$ with nonspecific monoclonal IgG $(20 \mu \mathrm{g} /$ $100 \mu \mathrm{l})$ as a blocker was added to the assay. The RIAs were performed either in the forward or simultaneous sandwich mode (23-26) with incubation times varying from 0.5 to $24.0 \mathrm{~h}$. Incubation temperature ranged from $4^{\circ} \mathrm{C}$ to $45^{\circ} \mathrm{C}$. After incubation with the test sample, the beads were washed three times with distilled water and counted in a gamma well counter assay. Assay standards were composed of purified PTP diluted in normal human serum.

Immunohistochemistry. Human liver, pancreas, kidney, gall bladder, duodenum, jejunum, colon, and pancreatic carcinoma obtained at the time of surgery were fixed for $2 \mathrm{~h}$ in $10 \%$ formaldehyde-PBS. The fixed tissues were embedded in paraffin, sectioned, and stained with an avidinbiotin horseradish peroxidase conjugated probe as previously described (27). In addition, 38 human tissue cell lines obtained from the American Type Tissue Culture Collection, as well as other cell lines developed in our laboratory for other purposes (28) were prepared as monolayer cultures and similarly examined for the presence of PTP.

\section{Results}

The isolation of thread protein from human pancreas obtained at autopsy proceeded very much as did the extraction and purification of bovine PTP (8). Recovery of $22.4 \mathrm{mg}$ of lyophilized, purified human PTP was obtained from $570 \mathrm{~g}$ of whole wet pancreas. No effort was made to defat the tissue or to produce a dry powder since previous efforts at isolation from bovine pancreas powder had been unsuccessful.

Of some interest, because of the remarkable linear ordering potential of this protein, was the observation that the initial precipitate of threads from the final fraction of the pancreas extraction procedure appeared in the form of discrete, spherically laminated globules ranging from 0.1 to $0.3 \mathrm{~mm}$ in diameter (Fig. 1 $A$ ). In the polarizing microscope, these globules revealed a well defined Maltese cross indicating a highly ordered spherical array of radially oriented, positively birefringent (as determined with a quarter wave plate) filamentous units (Fig. $1 B$ ). Where the globules were in close proximity, there appeared to be tangentially oriented bundles or sheets of positively birefringent filamentous material. Centrifugation of this suspension produced a compact white pellet that dissolved readily in $0.1 \mathrm{~N} \mathrm{HCl}$. After further purification of acid solubilized material by cycling from acid to neutral $\mathrm{pH}$, it was not possible to reconstitute these unusual globular structures.

Electron microscopy of fresh cloudy pancreatic fluid or of a suspension of purified threads after repeated $\mathrm{pH}$ cycling showed masses of very long, unkinked filaments of uniform diameter usually lying in parallel bundles, although seen frequently as individuals (Fig. $2 A$ ). The ends of these filaments were never tapered and high magnification pictures failed to show any repeating pattern by either negative staining (Fig. $2 B$ ) or metal shadowing. Threads from these two sources were identical in morphology by electron microscopy. Helically wound threads similar to those seen in purified bovine pancreatic thread preparations (8) were never seen in any of the pancreatic fluids or those prepared from tissue extracts.

pH Dependence of solubility. Lyophilized human PTP dissolved instantly and completely in hydrochloric acid or acetic acid below pH 4.6 to form a nonviscous solution even at concentrations of $1 \%$. As observed for the bovine PTP, these reconstituted to an opalescent gel upon neutralization. This gel-sol transformation was freely repeatable for an indefinite number of cycles. The presence or absence of sodium chloride up to 0.2 $M$ failed to influence this phenomenon appreciably and the same cycling was readily obtained in citrate-phosphate buffers. A more precise characterization of the $\mathrm{pH}$ dependence of solubility was obtained by using a series of citrate-phosphate buffers ranging in $\mathrm{pH}$ from 2.6 to 10.5 . The pattern of solubility as a function of $\mathrm{pH}$ is shown in Fig. 3. The protein began to precipitate significantly above $\mathrm{pH} 4.6$ and remained soluble until pH 9.2, above which it returned to solution. No threads were seen by electron microscopy below $\mathrm{pH} 3.8$ or above $\mathrm{pH} 9.8$. These observations were paralleled by the amount of sediment visible by eye after centrifugation and by quantitative turbidity measurements before centrifugation (data not shown). This $\mathrm{pH}$ dependence pattern is very similar to that of the bovine threads except that the latter begin to precipitate at a lower $\mathrm{pH}(8)$.

Homogeneity and molecular weight. $\mathrm{NaDodSO}_{4}$ polyacrylamide gel electrophoresis of purified human PTP indicated the presence of one major band, often but not always, accompanied by a closely associated much fainter staining, slower moving component not apparent in Fig. 4 but visible in Fig. 8, top. The apparent molecular weight of the major band is $\sim 14,000$ (Fig. 4 , lane 2). On reduction and alkylation the minor band disappeared and the major component now migrated more slowly, with an apparent molecular weight of 15,500 (Fig. 4, lane 3). The reduced and alkylated preparations were tagged with iodo $\left[{ }^{14} \mathrm{C}\right]$ acetamide and a radioautograph indicated labeling of the major band only (not shown).

Variable amounts of proteolytic activity at neutral $\mathrm{pH}$ were identified in different preparations of purified PTP. However, we were able to show by electrophoresis in gelatin-impregnated $\mathrm{NaDodSO}_{4}$ gels that the enzymatic activity migrated separately from the thread protein (Fig. 5, lane 3) and in the range of trypsin activity (lane 2). Trypsin itself does not stain with Coomassie Blue or Amido Black in the bands of gelatinase activity because of its very low amount, i.e., $50 \mathrm{ng}$. Similarly, the concentration of proteases in PTP is below the detection level and therefore is negligible in amounts compared with PTP. 

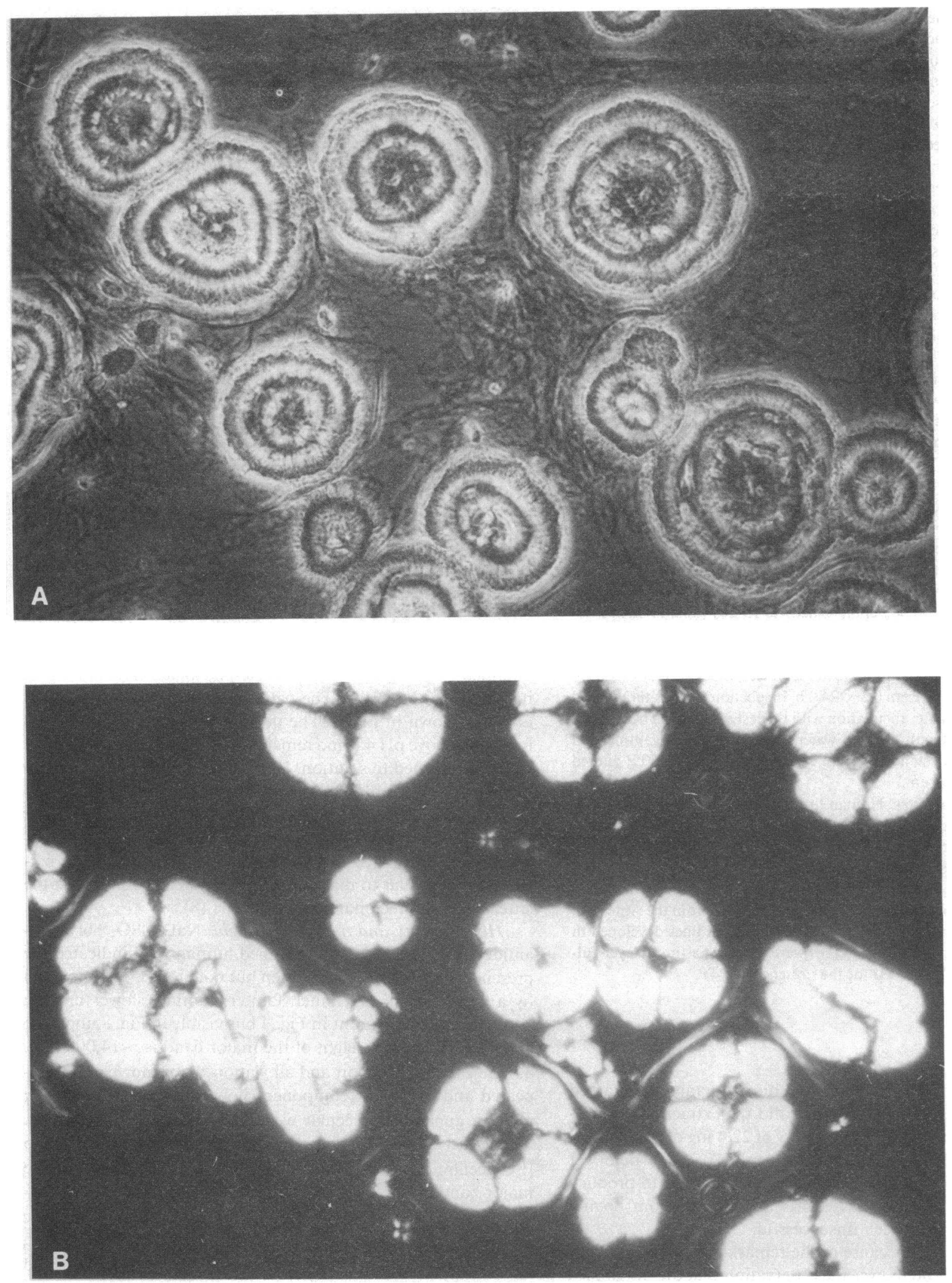

Figure 1. Precipitate formed at last step in isolation of human PTP from fresh pancreas. $(A)$ Phase contrast micrograph of a drop of suspension. Magnification, $\times 225$. (B) Polarized light micrograph of same preparation shown in $A$ showing a Maltese Cross in each spherite, which indicates radially oriented filamentous units (see Results). Magnification, $\times 225$. 

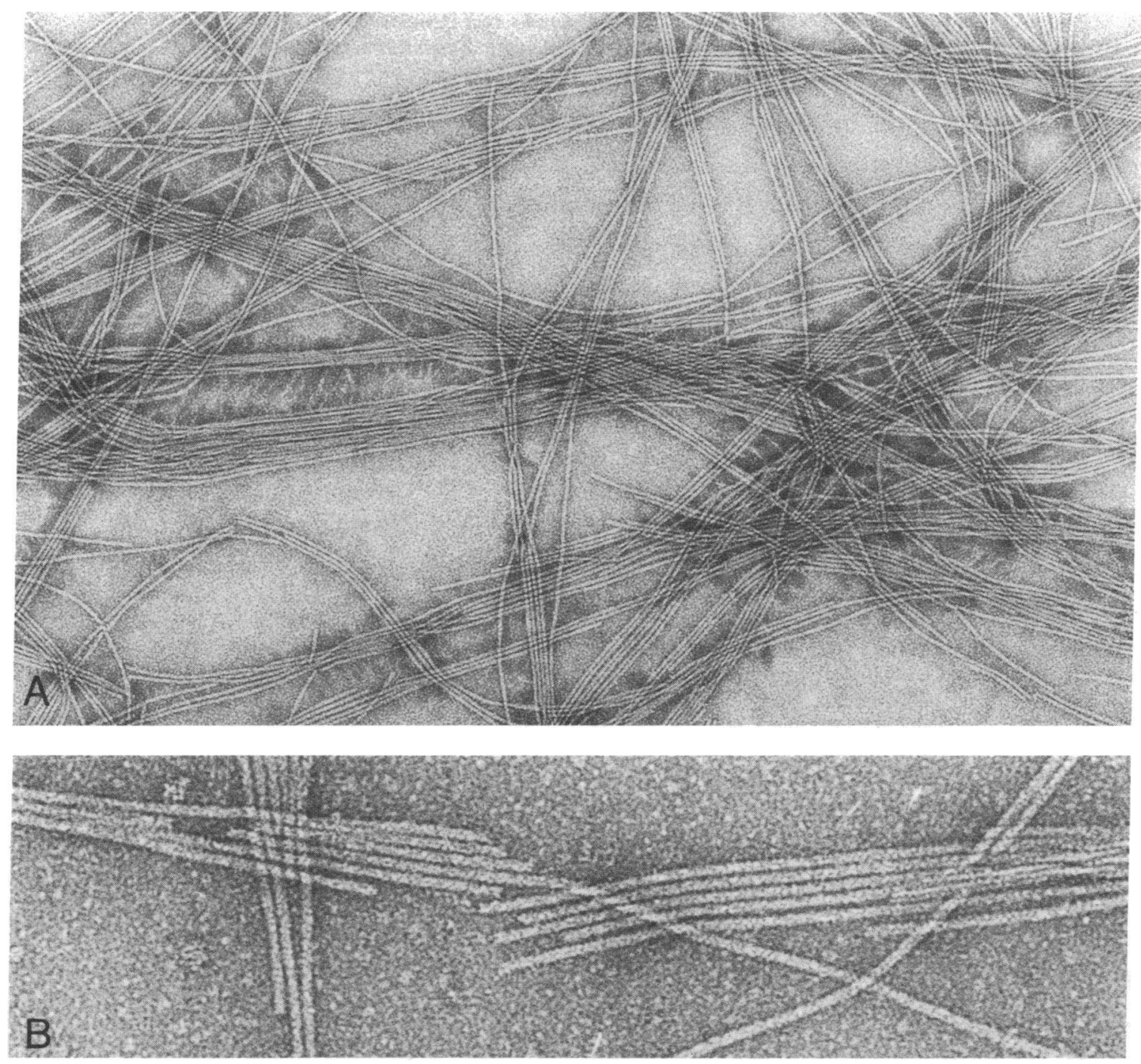

Figure 2. Electron micrograph of suspension of threads in fresh normal pancreatic fluid. Negatively stained with sodium silicotungstate. $(A) \times 79,200$. $(B) \times 197,000$.

Amino acid composition. The amino acid composition of both human and bovine PTP is distinguished by the high aspartic acid/asparagine, glutamic acid/glutamine, serine, and aromatic amino acid content (Table I). The tryptophan content is higher than that for any other known pancreatic protein. Also of interest is the absence of any significant amount of carbohydrate, fatty acid, or protein-bound phosphate.

Primary structure. Amino acid sequence analysis of both tissue and secretion derived PTP revealed a single continuous

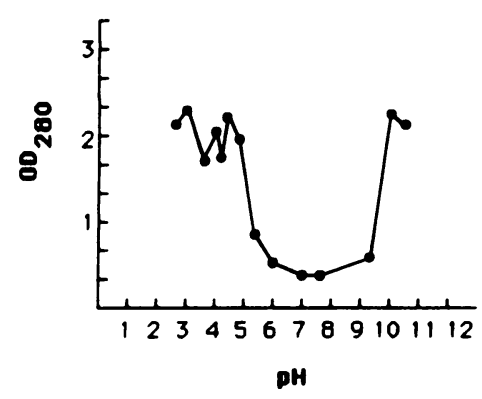

Figure 3. pH dependence of solubility of human PTP. Absorption of $280 \mathrm{~mm}$ of clear supernatant fluid after removal of undissolved portion by centrifugation at each $\mathrm{pH}$ value. sequence for 45 cycles except for positions 3,14 , and 31 , where no Pth amino acid was identified. A repeat degradation on completely reduced and radioalkylated PTP extended the sequence to 45 cycles with Pth $S$-carboxymethylcysteine identified at the three missing residues. This sequence is identical with 26 of the first 45 positions ( $58 \%$ homology) in the A chain of bovine PTP. Both sequences are compared in Fig. 6. Cysteine residues were present in the same positions, 3,14 , and 31 in the homologous chains.

RIA analysis with monoclonal antibodies to human PTP. We established 23 clones producing anti-human PTP antibodies as determined by the ELISA assay (data not shown). The isotypes of these antibodies produced by double clonal cell lines were of the IgG class. These monoclonal antibodies appeared to recognize distinct and separate determinants on human PTP by competitive binding experiments (data not shown). We then explored the effects of various monoclonal anti-PTP antibodies, either alone or in combination, in the construction of multisite RIAs for the measurement of human PTP. Table II demonstrates a representative experiment where various combinations of antiPTP antibodies have been linked to the solid phase support in 



Figure 5. Zymogram of PTP on an $\mathrm{NaDodSO}_{4}$ gelatin-polyacrylamide gel. Lanes 1 and 4, molecular weight markers same as for Fig. 4 (k, mol wt). Lane 2, trypsin $50 \mathrm{ng}$, which after removal of $\mathrm{NaDodSO}_{4}$ and incubation, lysed the gelatin and appeared after staining with Coomassie Blue as a nonstained band. Lane 3, purified PTP, showing wide separation of the thread protein (stained) from the proteolytic activity (nonstained band).
Table I. Amino Acid Composition of Human Pancreatic Thread Protein

\begin{tabular}{|c|c|c|c|}
\hline \multirow[b]{2}{*}{ Amino acid } & \multirow[b]{2}{*}{ Residue/1,000* SD } & \multicolumn{2}{|c|}{ Residues/mol } \\
\hline & & Human‡ & Bovine§§" \\
\hline Aspartic acidT & $131.6 \pm 6$ & 18 & 23 \\
\hline Threonine & $46.4 \pm 1$ & 6 & 7 \\
\hline Serine & $127.3 \pm 4$ & 17 & 23 \\
\hline Glutamic acid $\pi$ & $72.0 \pm 1$ & 10 & 12 \\
\hline Proline & $38.2 \pm 3$ & 5 & 8 \\
\hline Glycine & $38.2 \pm 3$ & 10 & 11 \\
\hline Alanine & $52.0 \pm 3$ & 7 & 10 \\
\hline Cys/2 & $42.2 \pm 2$ & 5 & 6 \\
\hline Valine & $63.2 \pm 5$ & 9 & 7 \\
\hline Methionine & $9.0 \pm 1$ & 2 & 2 \\
\hline Isoleucine & $27.6 \pm 1$ & 3 & 5 \\
\hline Leucine & $56.4 \pm 4$ & 8 & 11 \\
\hline Tyrosine & $52.0 \pm 1$ & 7 & 6 \\
\hline Phenylalanine & $50.0 \pm 2$ & 7 & 3 \\
\hline Lysine & $70.4 \pm 3$ & 10 & 6 \\
\hline Histidine & $15.0 \pm 1$ & 2 & 4 \\
\hline Arginine & $30.4 \pm 3$ & 4 & 5 \\
\hline \multirow[t]{2}{*}{ Tryptophan } & $35.2 \pm 4$ & 5 & 8 \\
\hline & & \multicolumn{2}{|c|}{$\mathrm{mol} / \mathrm{mol}$} \\
\hline $\mathrm{CHO}$ & & \multicolumn{2}{|c|}{$<0.1$} \\
\hline Fatty acids & & \multicolumn{2}{|c|}{$<0.1$} \\
\hline Phosphates (bound) & & \multicolumn{2}{|c|}{$<0.1$} \\
\hline
\end{tabular}

* Mean $\pm \mathrm{SD}, n=5$.

$\ddagger M_{\mathrm{r}}, 14,000$.

$\S M_{\mathrm{r}}, 17,800$.

"Reference (8).

II Includes amides.

order to assess their effect on assay sensitivity. In these experiments the indicator probe was the HT-110 ( $\left.\operatorname{lgG}_{2 \mathrm{a}}\right)$ antibody labeled with ${ }^{125}$ I. It was striking that a combination of HT-110 and $\mathrm{HT}-7\left(\mathrm{IgG}_{1}\right)$ on the bead increased the sensitivity approximately 100 -fold compared with the other combinations with HT-9 $\left(\operatorname{lgG}_{1}\right)$. Experiments were performed where time of incubation, temperature, and assay design ("simultaneous" vs.

\section{Sequence Comparison between Human and Bovine (Chain A) PTP}

$\begin{array}{llll}1 & 5 & 10 & 15\end{array}$

Human PTP: Ile Ser Cys Pro Glu Gly Thr Asn Ala Trr Arg Ser Tyr Cys Tyr Bovine PTP: Ile Ser cys pro Ser Gly Ser Met Ala Tyr Arg Ser His Cys Tyr (Chain A)

$$
16
$$$$
20
$$$$
25
$$

Human PTP: Tyr Phe Asn Glu Asp Arg Glu Thr Trp Val Asp Ala Asp Leu Tyr Bovine PTP: Ala Leu Phe Lys Thr Pro Lys Thr Trp Met Asp Ala Asp Ile Ala $\begin{array}{llll}\text { (Chain A) } & 31 & 35 & 40\end{array}$ Human PTP: Cys Gln Asn Met Asn Ser Gly Asn Leu Val Ser Val Leu Thr Gin Bovine PTP: Cys Gin Lys Arg Pro Ser Gly His Leu val Ser val Leu Ser Gly Ala Phe Phe
(Cha in A)

Figure 6. Amino acid sequence of 45 residues from the amino-terminal end of reduced and radioalkylated human PTP. Comparison with the sequence of the amino-terminal 48 residue fragment of the A chain of bovine PTP. Homologous amino acids are linked by a vertical line. 
Table II. Effect of Various Combinations of Monoclonal Antibodies on Radioimmunoassay Sensitivity

\begin{tabular}{|c|c|c|c|c|c|}
\hline \multirow[b]{2}{*}{ Antigen* } & \multicolumn{5}{|c|}{ Antibodies bound to soluble phase support } \\
\hline & HT -110 & HT-7 & HT-9 & $\begin{array}{l}\text { HT-110 } \\
+ \text { HT-7 }\end{array}$ & $\begin{array}{l}\text { HT- } 100 \\
+ \text { HT-9 }\end{array}$ \\
\hline \multicolumn{6}{|l|}{$\mu g / m l$} \\
\hline 100 & $257 \S$ & 3.8 & 2.9 & 26.5 & 13.2 \\
\hline 10 & 309 & 2.5 & $\underline{2.3}$ & 16.5 & 11.6 \\
\hline 1 & 41 & $\underline{2.4}$ & $\overline{1.98}$ & 4.4 & 9.7 \\
\hline 0.1 & 1.14 & $\overline{1.99}$ & 1.48 & 3.4 & 3.7 \\
\hline 0.01 & 0.85 & 1.60 & 1.35 & 3.0 & 1.5 \\
\hline 0.0001 & 0.96 & 1.07 & - & 2.3 & - \\
\hline 0.0001 & 0.70 & - & - & 0.5 & - \\
\hline
\end{tabular}

* Purified thread protein diluted in normal human serum. $\ddagger$ In all experiments HT-1 10 was the ${ }^{125} \mathrm{I}$-radiolabeled indicator. It was added at $\sim 100,000 \mathrm{cpm}$ per assay (sp act, $10-15 \mu \mathrm{ci} / \mu \mathrm{g}$ ).

$\S \mathrm{S} / \mathrm{N}$ ratio defined as the mean cpm bound in the serum samples containing HPTP divided by the mean cpm of negative control serum. A result of $\mathrm{S} / \mathrm{N}>2.0$ was considered positive.

"forward" sandwich) were varied; we found that the optimal procedures for measurement of human PTP in biological fluids was the 2-h incubation, "forward sandwich" RIA performed at $37^{\circ} \mathrm{C}$ (data not shown). Results from these studies allowed us to construct a standard curve for PTP dispersed in normal human serum as shown in Fig. 7. This multisite RIA employing monoclonal HT-110 and HT-7 antibodies has a lower limit of sensitivity of $\sim 160 \mathrm{pg} / \mathrm{ml}$ as determined on 10 replicate measurements on PTP standards. The immunoassay appears capable of detecting human PTP over a wide range of concentrations.

To further assess the specificity of the RIA and to ascertain



Figure 7. Standard curve of the multisite RIA for PTP diluted in normal serum. Note that the RIA detects PTP over a large concentration range. Lower limit of sensitivity is $\sim 100-200 \mathrm{pg} / \mathrm{ml}$. the purity of the isolated thread protein, RIA analysis of the extracts of each $2-\mathrm{mm}$ slice of the $12 \%$ electrophoresis running gel was performed (Fig. 8). Because of resolution limitations of the slice method it was difficult to determine precisely which of the two closely associated bands were labeled or whether both represented the antigen. However, immunoblot analysis (not shown) identified the faster major band as the antigen. In addition, a slower band more lightly labeled with antibody appeared at a molecular weight of $\sim 26,000$. A faint band of higher molecular weight material at the same position was also identifiable by silver staining. This band may also be reflected in a small peak of antibody binding in the RIA-slice analysis migrating at an $M_{\mathrm{r}}$ between 23,000 and 29,000 (three replicate runs) seen in Fig. 8.

Tissue distribution of human PTP. Fig. 9 summarizes the results of RIA analysis of neutralized acid extracts of various tissues, pancreatic fluid, bovine trypsin, trypsinogen, and bovine PTP. The thread protein was uniformly present in all human pancreatic extracts and fluids examined although in widely varying amounts among the different specimens. It was also identified in two of three duodenal tissue extracts and in borderline amounts in jejunum. More importantly, PTP was not detected in neutralized acid extracts of any other tissue studied including stomach, liver, kidney, colon, gall bladder, parotid, or various regions of the brain. Moreover, the monoclonal antibodies used in the RIA did not identify cross-reactive epitopes on purified bovine PTP, trypsin, or trypsinogen. In contrast to the localization of PTP in normal pancreas, this protein was not detected in three pancreatic adenocarcinoma extracts. Thus, the human pancreatic thread protein appears to have remarkable specificity for the normal human pancreas. Finally, we examined 100 sera obtained from normal blood donors for the presence of PTP; none were reactive in the RIA.

Immunoassay of pancreatic secretion. After electron microscopic studies had identified threads in pancreatic fluid, additional quantitative studies were done on these fluids. In this regard we were fortunate to have obtained for study a patient with a normal pancreas and external pancreatic fistula where sufficient amounts of normal pancreatic secretion were available for analysis. Fig. 10 represents an RIA analysis of dilutions of this secretion, which indicated a concentration of $\sim 300 \mu \mathrm{g} / \mathrm{ml}$.

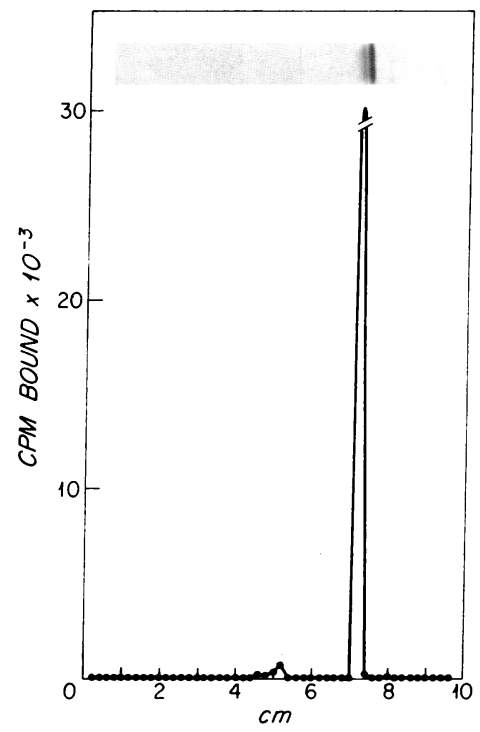

Figure 8. RIA analysis of PTP electrophoresed in $12.5 \% \mathrm{NaDodSO}_{4}$ polyacrylamide gel. Gel was sectioned into 2-mm slices; each fraction was dissolved in PBS and immunoreactivity was determined. All immunoreactive protein was localized to one fraction. The gel pattern stained with Coomassie Blue is shown at top. 


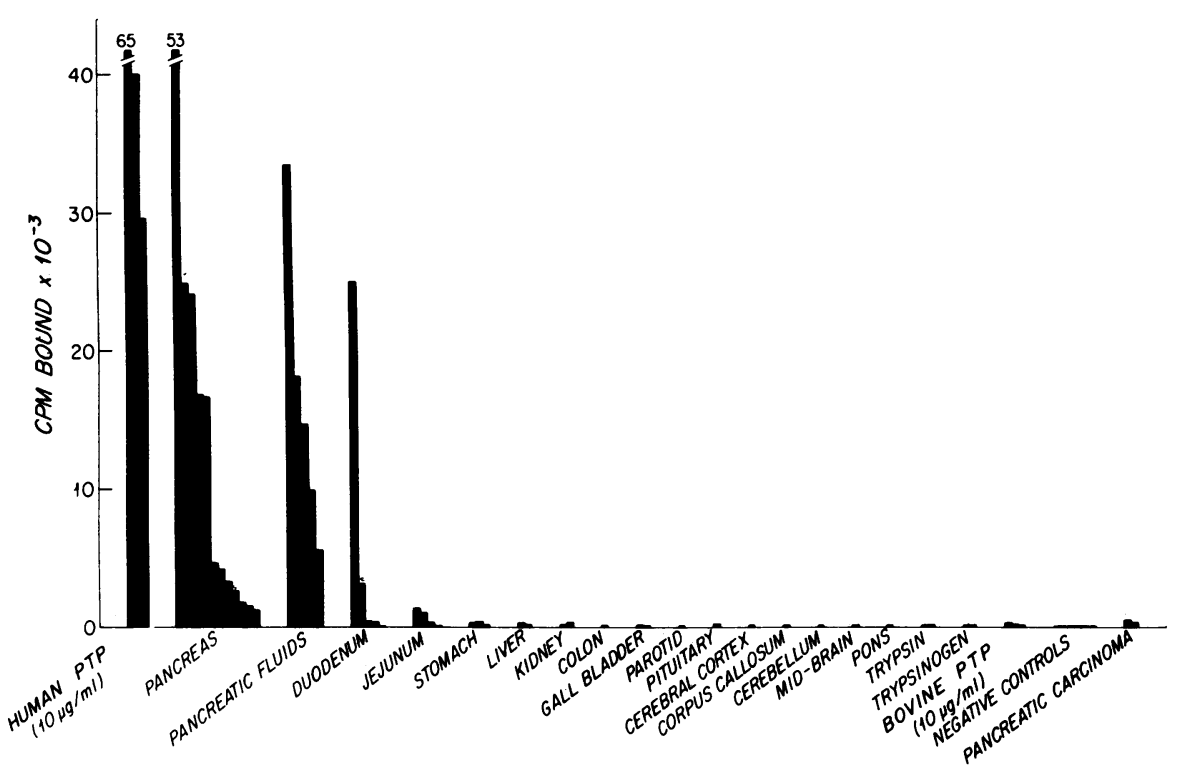

Figure 9. Measurement of human PTP activity in various tissue extracts by RIA. Note that human PTP binding activity was absent in bovine PTP, trypsin, and trypsinogen. The vertical bars represent the different samples of each category studied.
Samples were applied at pH 2.6 (Fig. 11, lanes 1 and 2) and $\mathrm{pH}$ 7.4 (lanes 3 and 4) to $7.5 \%$ polyacrylamide $\mathrm{NaDodSO}_{4}$ slab gels. A strong, sharp band moving at the same apparent molecular weight as that of PTP confirmed it as being a major component of the secretion.

Immunohistology. Immunofluorescence and immunoperoxidase studies on frozen and also fixed sections of human pancreas using two different antibodies were strongly positive for acinar cells. Fig. $12 A$ shows the presence of PTP as discrete irregular accretions in the cytoplasmic domains of some but not all of the cells in any one pancreatic acina and occasionally in the duct lumen, by immunohistologic labeling with peroxidase using the monoclonal antibody, HT-110. Islet, stromal connec-

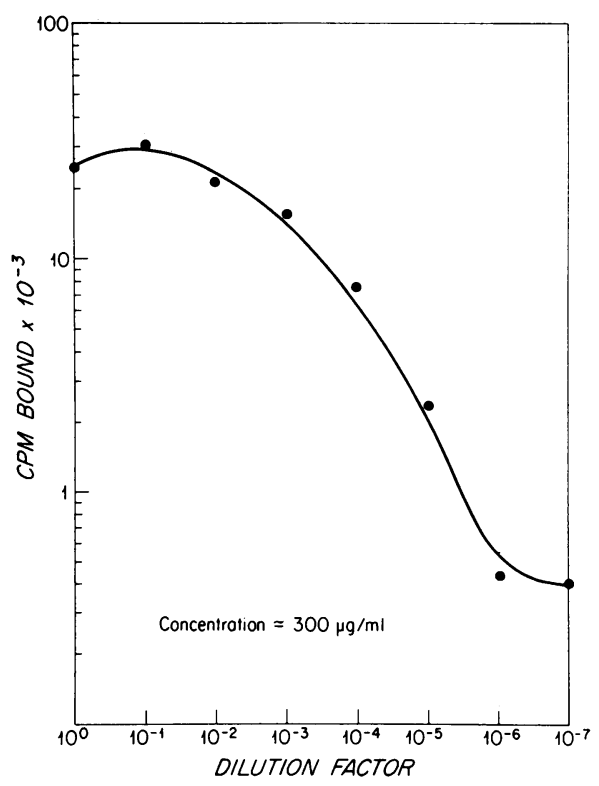

Figure 10. Quantitative determination of PTP in normal pancreatic fluid. Concentration was determined from the standard curve of purified PTP (See Fig. 7). tive tissue, and endothelial cells were negative for PTP. As shown in Fig. $12 \mathrm{~B}$, repeated staining of duodenum failed to demonstrate the presence of PTP, a finding in contrast to RIA analysis of neutralized acid extracts of this organ where low levels were found. The RIA positive results from duodenum are probably due, at least in part, to the presence of pancreatic secretion. We were unable to demonstrate the presence of PTP by immunofluorescence staining in $\mathbf{3 8}$ human tumor cell lines obtained from the American Type Tissue Culture Collection or in frozen sections of other human tissues and tumors including those of pancreas, as shown in Table III.

\section{Discussion}

The detection, isolation, and characterization of a protein obtained in a filamentous form exhibiting $\mathrm{pH}$-dependent globule fibril transformation, from normal human pancreatic tissue, described herein, was a direct consequence of the much earlier, accidental finding of a closely related thread-like protein with similar solubility behavior in commercially available crystallized bovine trypsinogen and trypsin $(2,3)$.

The human pancreatic thread protein isolated from acid extracts, precipitated from neutral solution under the same conditions as did bovine PTP but formed small globules in suspension, which were visible to the naked eye. These consisted of radially oriented asymmetric particles, visualized by electron microscopy as long, uniform threads. Other components are probably also involved, since these spherites could not be duplicated with the purified thread protein alone. Whether this "morphogenetic" potential reflects some function in vivo is unknown.

When we compared different samples of pancreatic secretions, some were cloudy with masses of threads while others were clear, yet all had demonstrable PTP by RIA. In several instances precipitation of threads in clear fluids occurred spontaneously on standing at $4^{\circ} \mathrm{C}$. In one instance, clearing the fluid by centrifugation was followed in a few days by clouding of the clear supernatant fluid with another crop of threads. This phenomenon suggests the presence of PTP in pancreatic fluid in a 


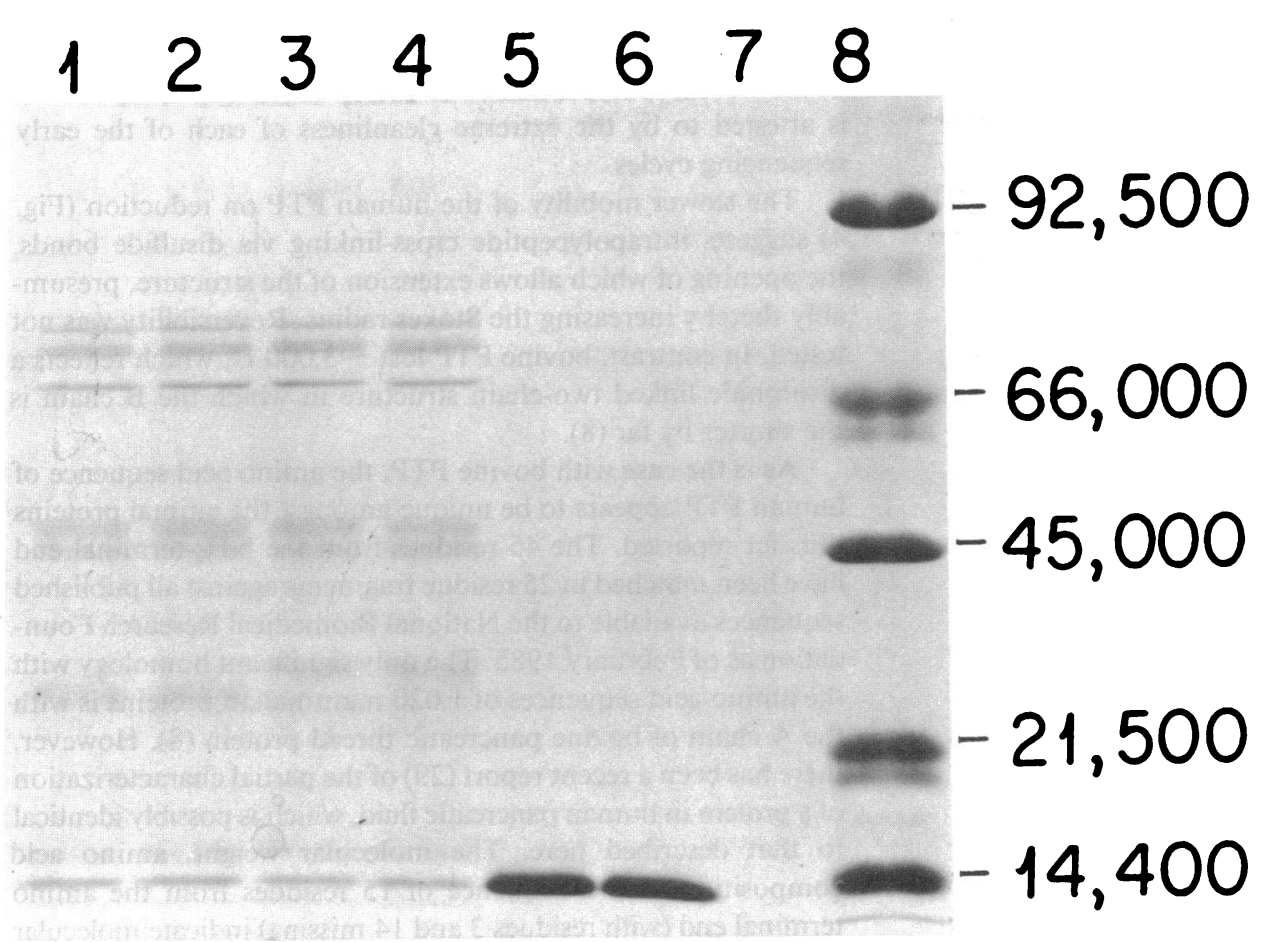

Figure $11.7 .5 \%$ polyacrylamide $\mathrm{NaDodSO}_{4}$ gel electrophoresis performed under nonreducing conditions demonstrating that PTP protein is a major component of normal pancreatic fluid. Lanes 1 and 2, pancreatic fluid, pH 7.4; lanes 3 and 4, pancreatic fluid, $\mathrm{pH} 2.6$; lanes 5 and 6 , purified PTP; lane 8 , molecular weight markers, same as for Fig. 4.
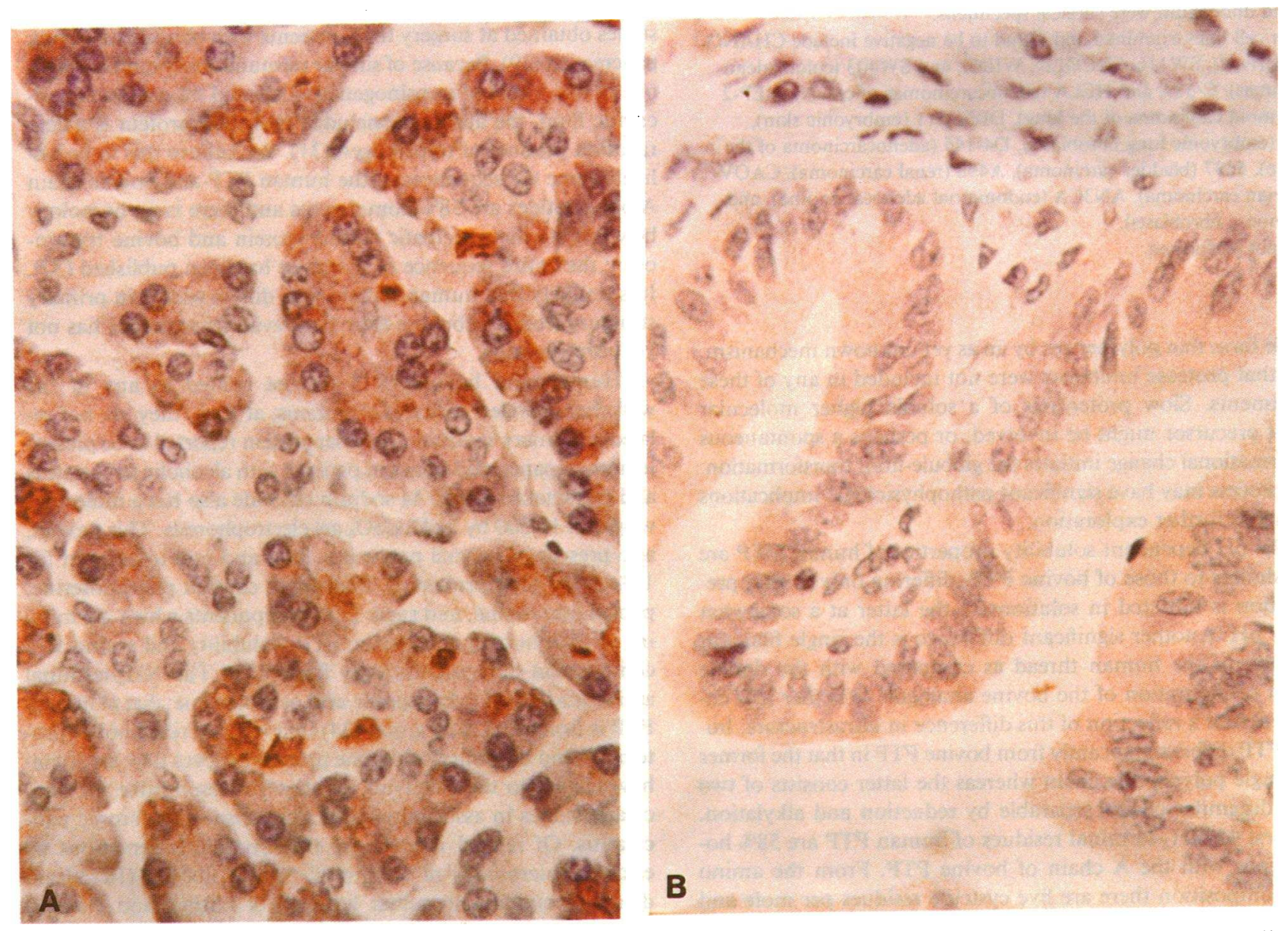

Figure 12. Immunoperoxidase staining of lightly fixed sections of normal fresh tissue of $(A)$ pancreatic acinar cells labeled with antibody HT 110 demonstrating the discrete accumulation of human PTP within the cytoplasm of some cells in each acina; $(B)$ sections of duodenum showing the lack of PTP staining in this organ. 
Table III. Summary of Immunofluorescence Staining Data

\begin{tabular}{llll}
\hline Cell line & Tissue origin* & Monoclonal antibodies \\
\hline & & HT-110 & HT-7 \\
& & +++ & +++ \\
- & Pancreas & - & - \\
- & Liver & - & - \\
- & Kidney & - & - \\
- & Duodenum & - & - \\
PLC/PRF/5 & Hepatoma & - & - \\
MALHAVU & Hepatoma & - & - \\
SK-HEP-1 & Hepatoma & - & - \\
FOCUS & Hepatoma & - & - \\
BT-20 & Breast adenocarcinoma & NA§ & - \\
SW-480 & Colon adenocarcinoma & NA & - \\
CACO-3 & Colon adenocarcinoma & NA & - \\
COLO-320 & Colon adenocarcinoma & NA & - \\
SK-MEL-6 & Melanoma & NA & - \\
U87-M6 & Glioblastoma & NA & - \\
A427 & Lung carcinoma & NA & - \\
SK-UT-1 & Mesodermal carcinoma & NA & - \\
JEG-3 & Choriocarcinoma & NA & - \\
HUTN-80 & Duodenal adenocarcinoma & - & - \\
CAPAN-2 $\ddagger$ & Pancreatic adenocarcinoma & - & \\
\hline & & & \\
\hline
\end{tabular}

* All are of human origin. Fresh frozen sections of pancreas, liver, kidney, and duodenum were surgical specimens.

$\ddagger$ Other cell lines examined and found to be negative include CHANG (liver derived), SW116, SKCOLD, WIDR, and SW403 (colon adenocarcinomas), C-33A and HELA (adenocarcinomas of cervix), HEP-2 (epidermoid carcinoma of the lung), DIET-511 (embryonic skin), HELF (embryonic lung fibroblasts), D4-145 (adenocarcinoma of the prostate), 5637 (bladder carcinoma), A498 (renal carcinoma), CAOV3 (ovarian carcinoma), AN3CA (endometrial adenocarcinoma), and 3T3 (mouse fibroblasts).

$\S \mathrm{NA}$, not performed.

soluble form that polymerizes by an as yet unknown mechanism. Note that protease inhibitors were not included in any of these experiments. Slow proteolysis of a soluble higher molecular weight precursor might be involved; or perhaps a spontaneous conformational change initiates the globule-fibril transformation. This process may have significant pathophysiologic implications and needs further exploration.

The $\mathrm{pH}$ dependent solubility properties of human PTP are very similar to those of bovine PTP, differing only in that precipitation is initiated in solutions of the latter at a somewhat higher $\mathrm{pH}$. Another significant difference is the single filament structure of the human thread as compared with the double helical configuration of the bovine analogue. Whether it is coincidental or a reflection of this difference in ultrastructure, human PTP differs significantly from bovine PTP in that the former is a single polypeptide chain whereas the latter consists of two quite dissimilar chains separable by reduction and alkylation. The first $45 \mathrm{NH}_{2}$-terminal residues of human PTP are 58\% homologous with the A chain of bovine PTP. From the amino acid composition there are five cysteine residues per mole and only three were present in the first 45 residues, leaving two more elsewhere in the molecule. In bovine PTP the other two are located in the B chain. Of interest is the homologous location of the three cysteine residues detected in the bovine A chain and in the human polypeptide. The purity of the PTP preparation is attested to by the extreme cleanliness of each of the early sequencing cycles.

The slower mobility of the human PTP on reduction (Fig. 4) suggests intrapolypeptide cross-linking via disulfide bonds, the opening of which allows extension of the structure, presumably thereby increasing the Stokes radius. Reversibility was not tested. In contrast, bovine PTP lost $\sim 3,000 \mathrm{D}$, which reflects a disulphide linked two-chain structure in which the $B$ chain is the shorter by far (8).

As is the case with bovine PTP, the amino acid sequence of human PTP appears to be unique amongst the animal proteins thus far reported. The 45 residues from the $\mathrm{NH}_{2}$-terminal end have been matched in 25 residue fragments against all published sequences available to the National Biomedical Research Foundation as of February 1985 . The only significant homology with the amino acid sequences of 1,020 mammalian proteins is with the A chain of bovine pancreatic thread protein (8). However, there has been a recent report (29) of the partial characterization of a protein in human pancreatic fluid, which is possibly identical to that described here. The molecular weight, amino acid composition, and a sequence of 15 residues from the amino terminal end (with residues 3 and 14 missing) indicate molecular identity (30) or close similarity. This protein was said to be immunocross-reactive in an Ochterlony test using a rabbit antiserum to pancreatic fluid, with one extracted from pancreatic stones obtained at surgery from patients with chronic calcifying pancreatitis (29). Because of similar immunocross-reactivity with one of two forms of trypsinogen also isolated from human pancreatic fluid, the authors concluded that their protein is a degradation product of trypsinogen (31). We believe this to be unlikely since the sequences of the human PTP and bovine chain A polypeptides are $58 \%$ homologous and there is no homology between bovine pancreatic thread protein and bovine trypsinogen; the entire sequence of the latter has been published (32). It is unlikely that human trypsinogen differs widely in primary structure from the bovine form; however, its sequence has not yet been reported.

Human and bovine PTP are not related to any of the well characterized pancreatic proteins; at least, they are not related in primary structure. Another protein reported to be present in human pancreatic stones in patients with alcoholic pancreatitis and extractable in $0.15 \mathrm{M}$ sodium chloride also has a molecular weight of 13,500 by $\mathrm{NaDodSO}_{4}$ gel electrophoresis. This protein, also present in normal pancreatic fluid and said to account for $14 \%$ of the total protein, is reported to contain phosphoserine, phosphothreonine, and sugar (33), components which are missing in both human and bovine PTP. Solubility and amino acid composition differ significantly from PTP. The $\mathrm{NH}_{2}$-terminal amino acid is said to be aspartic acid or asparagine; that of human PTP is isoleucine. The group (34) that has described both "protein X" and the pancreatic stone protein believes they are somehow related to the calcifying mechanism responsible for pancreatic stones in association with alcoholism and chronic pancreatitis. Of related interest are the reported observations by electron microscopy of Kern et al. (35) of fibrillar (10-30-nm diam) precipitates in acinar luminae of normal and diseased human pancreas. Scheele et al. (36) have identified two other proteins in the same molecular weight range in normal human pancreatic fluid, (pro)phospholipase $A_{2}(17,000 \mathrm{~mol} w t)$ and an 
unidentified "glycoprotein 4" (15,000 mol wt). The amino acid sequence of the former (37) is not homologous with that of PTP and the latter is periodic acid Schiff-sensitive (PAS)-positive, which indicates sugar in the structure. It is possible that a family of proteins of about the same molecular weight but differing in solubility properties and primary structure are quantitatively important components of normal pancreatic fluid. The members of this hypothetical family may have very different functions, none of which have been well defined thus far.

Of interest is the fact that PTP appears to be an exclusive pancreatic protein since we have found no evidence of it in 12 other tissues, including the various parts of the brain, using a sensitive and specific monoclonal radioimmunoassay on neutralized acidic tissue extracts and also by immunohistochemistry. In a few certain cases of pancreatic pseudocyst and acute pancreatitis, significant levels of PTP were detected by RIA in the serum. The assay was negative in 300 sera of both normal people and patients with a wide variety of nonpancreatic diseases (Wands et al., unpublished observations). More extensive studies on this point are in progress.

Although the thread protein appears to be a secretory product, it is possible that it represents a cytoplasmic filament of some type. An increasing variety of cytoplasmic filamentous proteins has been described and no doubt new ones will be found. Structures such as several of the intermediate filaments, when purified and isolated, might well resemble human pancreatic threads in dimensions and appearance. However, in all cases in which subunits have been isolated, the monomer appears to be much higher in molecular weight, ranging from $52,000 \mathrm{~mol} \mathrm{wt}$ for the glial filament protein to fodrin $(240,000 \mathrm{~mol} \mathrm{wt})(38)$. Microfilamentous nets and aggregates have been described specifically for the apical region of rat pancreatic acinar cells (39). They are described as a heterogeneous population ranging in diameter from 50 to $100 \mathrm{~nm}$. None of the cytoplasmic filaments isolated to date appear to have the $\mathrm{pH}$ dependent solubility characteristics of the pancreatic thread proteins, nor are any of the reported sequences for such proteins homologous with that reported here or for the bovine protein (8).

Pig kidney transaminase in the helical filament form (40), amyloid fibrils (41), and filaments described and isolated from the brain of patients with Alzheimer (42) and Creuzfeldt-Jakob (43) disease and in isolates from animals with Scrapie (44), also "prions" (45) do not have the solubility characteristics or monomer size described here. Of some interest is the physical appearance of the fibrils of this group in that they appear to be double helical with dimensions and appearances not unlike those of bovine PTP.

However, morphological appearance is hardly a good criterion for molecular or functional homology. Our RIA assay of neutralized acid extracts of normal brain was negative for PTP; however, we have not yet carefully examined tissue from aged people or those with Alzheimer's disease. In addition, analysis of extracts may be inadequate since the paired helical filaments in these conditions are highly insoluble and probably crosslinked. Immunohistochemistry would be more appropriate.

It is possible that this protein serves some function in the lysosomes since it is soluble below $\mathrm{pH} 6$, or perhaps it serves in the packaging of secretion granules. Whether or not it is involved in pathology of the pancreas, as in duct stone formation for example (35), requires further exploration. Immunoelectron microscopy with monoclonal antibodies should help provide some answers, particularly with regard to possible localization in the acinar cell cytoplasm, organelles, or secretion granules.

\section{Acknowledgments}

The authors wish to thank Dr. Ronald A. Malt, Dr. Robert Schapiro, and Dr. Peter Kelsey, who kindly provided normal pancreatic fluid obtained via pancreatic duct catheterization.

This work was supported by grants AM-3564, AA-20666, HL-19259, and CA-35711 from the National Institutes of Health. Dr. Wands is the recipient of a Research Career Scientist Development Award AA-00048 from the National Institutes of Health.

\section{References}

1. Gross, J. 1949. The structure of elastic tissue as studied with the electron microscope. J. Exp. Med. 89:669-708.

2. Gross, J. 1951. Fiber formation in trypsinogen solutions: an electron optical study. Proc. Soc. Exp. Biol. Med. 78:241-244.

3. Gross, J. 1952. Reversible fibril formation exhibited by a protein in pancreatic extracts. Fed. Proc. 11:60.

4. Waugh, D. F. 1948. Regeneration of insulin from insulin fibrils by the action of alkali. J. Am. Chem. Soc. 70:1850-1857.

5. Jakus, M. A., and C. E. Hall. 1947. Studies on actin and myosin. J. Biol. Chem. 167:705-714.

6. Bailey, K. 1948. Tropomyosin, a new symmetric protein component. Biochem. J. 43:271-279.

7. Kunitz, M., and J. H. Northrup. 1948. Trypsinogen, trypsin, and trypsinogen inhibitor. In Crystalline Enzymes. J. H. Northrup, M. Kunitz, and R. M. Herriott, editors. Columbia University Press, New York. 99.

8. Gross, J., A. W. Brauer, R. L. Bringhurst, C. Corbett, and M. N. Margolies. 1985. An unusual bovine pancreatic protein exhibiting $\mathrm{pH}$ dependent globule-fibril transformation and unique amino acid sequence. Proc. Natl. Acad. Sci. USA. 82:5627-5631.

9. Liu, T.-Y., and Y. H. Chang. 1971. Hydrolysis of proteins with p-toluene-sulfonic acid: determination of tryptophan. J. Biol. Chem. 246: 2842-2848.

10. Trelstad, R. L., and K. R. Lawley. 1976. A simple economical buffer system for amino acid analysis. Anal. Biochem. 70:287-289.

11. Rheinhold, V. R. 1972. Gas-liquid chromatographic analysis of constituent carbohydrates in glycoproteins. In Methods in Enzymology. Vol. 25. C. H. W. Hirs and S. Timasheff, editors. Academic Press, New York. 244-249.

12. Heckers, H., K. Dittmar, F. W. Melcher, and H. O. Kalinowski. 1977. Silar 10 C, silar 9 CP, SP 2340 and OV-275 in the gas-liquid chromatography of fatty acid methyl esters on packed columns: chromatographic characterizations and molecular structures. J. Chromatogr. 135:93-107.

13. Cohen-Solal, L., J. B. Lian, D. Kossiva, and M. J. Glimcher. 1979. Identification of organic phosphorus covalently bound to collagen and non-collagenous proteins of chicken-bone matrix. Biochem. J. 177: 81-98.

14. Laemmli, U. K. 1970. Cleavage of structural proteins during the assembly of the head of bacteriophage T4. Nature (Lond.). 227:680-685.

15. Harris, E. D., Jr., and S. M. Krane. 1972. An endopeptidase from Rheumatoid synovial tissue culture. Biochim. Biophys. Acta. 258:566567.

16. Heussen, C., and E. B. Dowdle. 1980. Electrophoretic analysis of plasminogen activators in polyacrylamide gels containing sodium dodecyl sulfate and copolymerized substrate. Anal. Biochem. 102:196-202.

17. Smith, J. A., and M. N. Margolies. 1984. Complete amino acid sequence of the heavy-chain variable region from an $\mathrm{A} / \mathrm{J}$ mouse antigennonbinding monoclonal antibody bearing the predominant arsonate idiotype. Biochemistry. 23:4726-4732.

18. Wands, J. R., and V. R. Zurawski, Jr. 1981. High affinity mono- 
clonal antibodies to hepatitis B Surface antigen (HBsAg) produced by somatic cell hybrids. Gastroenterology. 80:225-232.

19. Bidart, J.-M., M. Osturk, D. H. Bellet, M. Jolivet, H. Gras-Masse, F. Troalen, C. J. Bohuon, and J. R. Wands. 1985. Identification of epitopes associated with hCG and hCG carboxyl terminus by monoclonal antibodies produced against a synthetic peptide. J. Immunol. 134:457464.

20. Bellet, D. H., J. R. Wands, K. J. Isselbacher, and C. Bohuon. 1984. Serum alpha-fetoprotein levels in human disease: perspectives from a highly specific monoclonal radioimmunoassay. Proc. Natl. Acad. Sci. USA. 81:3869-3873.

21. Lowry, O. H., N. J. Rosebrough, A. L. Farr, and R. I. Randall. 1951. Protein measurements with the folin phenol reagents. J. Biol. Chem. 193:265-275.

22. Fraker, P. J., and J. C. Speck, Jr. 1978. Protein and cell membrane iodinations with a sparingly soluble chloroamide, 1,3,4,6-tetra-chloro3a,6a-diphenylglycoluril. Biochem. Biophys. Res. Commun. 80:849-857.

23. Wands, J. R., R. A. Marciniak, K. J. Isselbacher, M. Varghese, G. Don, J. W. Halliday, and L. W. Powell. 1982. Demonstration of previously undetected hepatitis B viral determinants in an Australian aboriginal population by monoclonal anti-HBs antibody radioimmunoassay. Lancet i:977-980.

24. Wands, J. R., R. R. Bruns, R. I. Carlson, A. Ware, J. E. Menitove, and $\mathrm{K}$. J. Isselbacher. 1982. Monoclonal IgM radioimmunoassay for hepatitis B surface antigen: high binding activity in serum that is unreactive with conventional antibodies. Proc. Natl. Acad. Sci. USA. 79: 1277-1281.

25. Wands, J. R., M. A. Wong, J. Shorey, R. D. Brown, R. A. Marciniak, and K. J. Isselbacher. 1984. Hepatitis B viral antigenic structure: signature analysis by monoclonal radioimmunoassays. Proc. Natl. Acad. Sci. USA. 81:2237-2241.

26. Carlson, R. I., E. Ben-Porath, D. Shouval, W. Strauss, K. J. Isselbacher, and J. R. Wands. 1985. Antigenic characterization of human hepatocellular carcinoma: development of in vitro and in vivo immunoassays using monoclonal antibodies. J. Clin. Invest. 76:40-51.

27. Hsu, S-M., L. Raine, and H. Fanger. 1981. Use of avidin-biotinperoxidase complex $(\mathrm{ABC})$ in immunoperoxidase techniques: a comparison between $\mathrm{ABC}$ and unlabeled antibody (PAP) procedures. J. Histochem. Cytochem. 29:577-580.

28. He, L., K. J. Isselbacher, J. R. Wands, H. M. Goodman, C. Shih, and A. Quaroni. 1984. Establishment and characterization of a new human hepatocellular carcinoma cell line. In Vitro (Rockville). 20:493504.

29. De Caro, A., J. Lohse, and H. Sarles. 1979. Characterization of a protein isolated from pancreatic calculi of men suffering from chronic calcifying pancreatitis. Biochem. Biophys. Res. Commun. 87:1176-1182.

30. Guy-Crotte, O., M. Amouric, and C. Figarella. 1984. Characterization and $\mathrm{N}$-terminal sequence of a degradation product of 14,000 molecular weight isolated from human pancreatic juice. Biochem. Biophys. Res. Commun. 125:516-523.

31. Figarella, C., M. Amouric, and O. Guy-Crotte. 1984. Proteolysis of human trypsinogen I. Pathogenic implications in chronic pancreatitis. Biochem. Biophys. Res. Commun. 118:154-161.

32. Mikes, O., V. Holeysovsky, V. Tomasek, and F. Sorm. 1966. Covalent structure of bovine trypsinogen. The position of the remaining amides. Biochem. Biophys. Res. Commun. 24:346-352.

33. De Caro, A., L. Multigner, H. LaFond, D. Lombardo, and H. Sarles. 1984. The molecular characteristics of a human pancreatic acidic phosphoprotein that inhibits calcium carbonate crystal growth. Biochem. J. 222:669-677.

34. Guy, O., G. Robles-Diaz, Z. Adrich, J. Sahel, and H. Sarles. 1983. Protein content of precipitates present in pancreatic juice of alcoholic subjects and patients with chronic calcifying pancreatitis. Gastroenterology. 84:102-107.

35. Kern, H. F., A. L. Warshaw, and G. A. Scheele. 1984. Fine structure of protein precipitations in acinar lumina of the normal human pancreas and in chronic pancreatitis. In Pancreatitis-Concepts and classification. K. E. Gyr, M. V. Singer, and H. Sarles, editors. Elsevier Science Publishing Co., Inc., New York. 101-105.

36. Scheele, G., D. Bartelt, and W. Bieger. 1981. Characterization of human endocrine pancreatic proteins by two-dimensional isoelectric focusing sodium dodecyl sulfate electrophoresis. Gastroenterology. 80: 461-483.

37. De Haas, G. H., A. J. Slotboom, P. P. M. Bonsen, and L. L. M. van Deenen. 1970. Studies on phospholipase A and its zymogen from porcine pancreas. The complete amino acid sequence. Biochim. Biophys. Acta. 221:31-53.

38. Lazarides, E. 1980. Intermediate filaments as mechanical integrators of cellular space. Nature (Lond.). 283:249-256.

39. Bauduin, H., C. Stock, D. Vincent, and J. F. Grenier. 1975. Microfilamentous system and secretion of enzyme in the exocrine pancreas. J. Cell Biol. 66:165-181.

40. Olsen, B. R., G. Svenneby, E. Kvamme, B. Tveit, and T. Eskeland. 1970. Formation and ultrastructure of enzymically active polymers of pig renal glutaminase. J. Mol. Biol. 52:239-245.

41. Cohen, A. S. 1968. High resolution ultrastructure immunology and biochemistry of amyloid. In Amyloidosis. E. Mandema, L. Ruinen, J. H. Scholten, and A. S. Cohen, editors. Excerpta Medica Foundation Publishers, Amsterdam. 149-171.

42. Selkoe, C. J., H. Ihara, and F. Salazor. 1982. Alzheimer's Disease. Insolubility of partially purified paired helical filaments in sodium dodecyl sulfate and urea. Science (Wash. DC). 215:1243-1245.

43. Merz, P. A., R. A. Somerville, H. M. Wisniewski, L. Manuelidis, and E. E. Manuelidis. 1983. Scrapie-associated fibrils in CreutzfeldtJakob disease. Nature (Lond.). 306:474-476.

44. Merz, P. A., R. G. Rohwer, R. Kascsak, H. M. Wisniewski, R. A. Somerville, C. J. Gibbs, Jr., and D. C. Gajdusek. 1984. Infectionspecific particle from the unconventional slow virus diseases. Science (Wash. DC). 225:437-440.

45. Prusiner, S. B., M. P. McKinley, K. A. Bowman, D. C. Bolton, P. E. Bendheim, D. F. Groth, and G. G. Glenner. 1983. Scrapie prions aggregate to form amyloid-like birefringent rods. Cell. 35:349-358. 